\title{
Research Opportunities on the Application of the Theory of Constraints to Software Process Development
}

\author{
Sildenir Alves Ribeiro ${ }^{1,2}$, Eber Assis Schmitz ${ }^{1}$, Antônio Juarez S. M. de Alencar ${ }^{1}$, Monica \\ Ferreira da Silva ${ }^{1}$ \\ ${ }^{1}$ The Tércio Pacitti Institute, Federal University of Rio de Janeiro, RJ, Brazil. Av. Athos da Silveira Ramos, 274, \\ University City, Brazil \\ ${ }^{2}$ Coordination of Industrial Automation, Federal Center of Technological Education of Rio de Janeiro, RJ, \\ Brazil, St. Miguel Angelo, 96 - Maria da Graça, Brazil \\ *Corresponding author. Tel.: +55 (21) 39383224 email: sildenir.ribeiro@ppgi.ufrj.br; eber@nce.ufrj.br \\ Manuscript submitted February, 2017; accepted April 10, 2017. \\ doi: 10.17706/jsw.12.4.227-239
}

\begin{abstract}
The software development process is a key factor in the efficient production of quality software. Software process improvement has been a constant theme not only in academia but also in the software industry, where countless works have been developed and published. The Theory of Constraints (TOC) was originally proposed by the physicist Eliyahu Moshe Goldratt, in the $80 \mathrm{~s}$ as a method for the continuous improvement of manufacturing processes. This research aims to survey the academic research on the application of the TOC to the software development process. We also searched for its application to other productive environments in an attempt to visualize approaches that could be adapted to the software development process, such as studies about process optimization, process improvement and process scheduling. The results showed research opportunities both theoretical and practical with application of the TOC in software process development, software process improvement, identification and treatment of bottlenecks in software process, optimization of software process and applications using heuristics, meta heuristics, mathematical models and optimization models.
\end{abstract}

Key words: Theory of constraints, software process development, literature review, process optimization.

\section{Introduction}

The Theory of Constraints (TOC) was originally proposed by Israeli physicist Eliyahu Moshe Goldratt, in the 80s as a method for the continuous improvement of manufacturing processes. TOC can be described as a philosophy of continuous improvement, which has evolved and expanded its methodological basis over time [1]-[15]. TOC has been the subject of a substantial amount of research involving its application to the manufacturing process.

TOC management philosophy incorporates a practical aspect to decision-making within the production environment, based on the principle that any limiting factor of a system output points to a system constraint. Using a chain as an analogy to a system, a constraint would be the weakest link or "the fat boy" as cited in [1]. TOC states that every system has at least one constraint [1], [2] and [17]. A constraint is any value that can prevent a system from achieving its goal [6]. According to [1] and [2], a constraint can be external (not physical) or internal (physical). The external constraints are usually associated with circumstantial problems, such as: (1) market demand: production over market capacity or production 
below market capacity; and (2) a corporate procedure: in this case, a decision or a procedure that limits the gain. The internal constraints are usually physical and are associated with the resources. According to [1] and [2] the external constraints are of three types: (1) equipment: this is related to the usability and productive capacity of the equipment; (2) people: involves the lack of qualified people, the productive capacity of the people and behavioral aspects; and (3) policy: the adoption of written policies, such as: laws, standards and regulations, can be a limiting factor for the productive system.

TOC requires that the system's goals have already been established and structured before the start of the Continuous Improvement Process (CIP) [13]. The CIP is divided in five stages [3] and [2] aimed to ensure that the improvement efforts are centered on organizational constraints [19]:

- IDENTIFY system constraints;

- EXPLORE the system constraints to take full advantage of the restrictions;

- SUBORDINATE decisions through the alignment of the whole system or organization to support decision making;

- ELEVATE the constraints of the system, making other major changes to increase the capacity of constraint;

- RETURN to the previous steps, if after the execution of the steps a constraint is broken, and thus, do not allow the INERTIA to create a new constraint in the system.

The software development process (SDP), as well as any manufactured product, requires the same or even more insightful demands during its construction cycle. As in any manufacturing process, SDP is influenced by internal and external variables. Furthermore, ethnological issues, due to the characteristics of the development teams, have a direct influence on the development process, making the development environment complex and highly dynamic.

Our aim in this research is to identify research opportunities that can lead to insights and improvements in the SDP through the application of the concepts and methodology widely used in industrial process management - the TOC.

\section{Literature Review}

The avalanche of scientific papers published each year makes it very difficult, even for a very specific topic, to analyze all of them. Academic works are increasingly multidisciplinary and embracing and even with the technological resources available, such as software, search sites and databases organized by subject areas, this analysis is a very time-consuming and difficult task.

Moreover, the misuse of these tools may lead to three types of errors when processing the collected information [5] and [12]. The first one, elimination, is the suppression of some information considered not fundamental in order to give place to another considered fundamental. The second one, distortion, is the substitution of information to adjust a given need, without proper analysis of this information or the sources that surround it. The third is generalization, which consists in the grouping of experiences considered similar or because they have some element in common, but which are not always really correlated.

A secondary study in software engineering is called of Systematic Literature Review (SLR) [7]. An SLR can still be typed in Systematic Mapping Review and Tertiary Review [7], [8] and [16]. This work can be classified as a systematic mapping aiming to identify potential research areas in SDP improvement using the Theory of Constraints (TOC).

\subsection{Framework for Review}

The process adopted for this review is organized in three phases, as suggested by [6], [9], [12], [16] and 
[18].

- Review Planning: this phase consists of three stages [14] and [16]. The first, Review Protocol: that defines the purpose and objectives of the research, sources consulted, strategies and criteria adopted for document selection, data extraction and prospecting of results. The second, Specificity of Research: that defines the thematic area according to the object end of the research. Finally, Search Method: that defines how the search will be performed, including search criteria, key words, search strings and choice of repositories.

- Conducting the Review: consists of search procedures, using the established criteria, on specified sources or repositories. Also at this stage, the primary studies are selected, read and analyzed, [6] and [12]. The phase is completed by the exclusion or acceptance of a document [11]. A document is excluded if not approved in at least one of the criteria adopted to validate the selection [10]. The inclusion of a document should be guided by the criteria established in the review protocol and aligned with the research objectives [16]. Eventually, new search or new evaluation criteria can be adopted to validate the review and acceptance process [4].

- Reporting the Review: this phase starts with the definition of format used to present the results of the review [7]. Systematic reviews are usually reported in at least two formats: (1) in a technical report or in a section of a doctoral thesis; or (2), in a journal or conference paper [7].

The three phases presented in the Fig. 1 below, represent the framework used to execute the systematic mapping process used in this work.

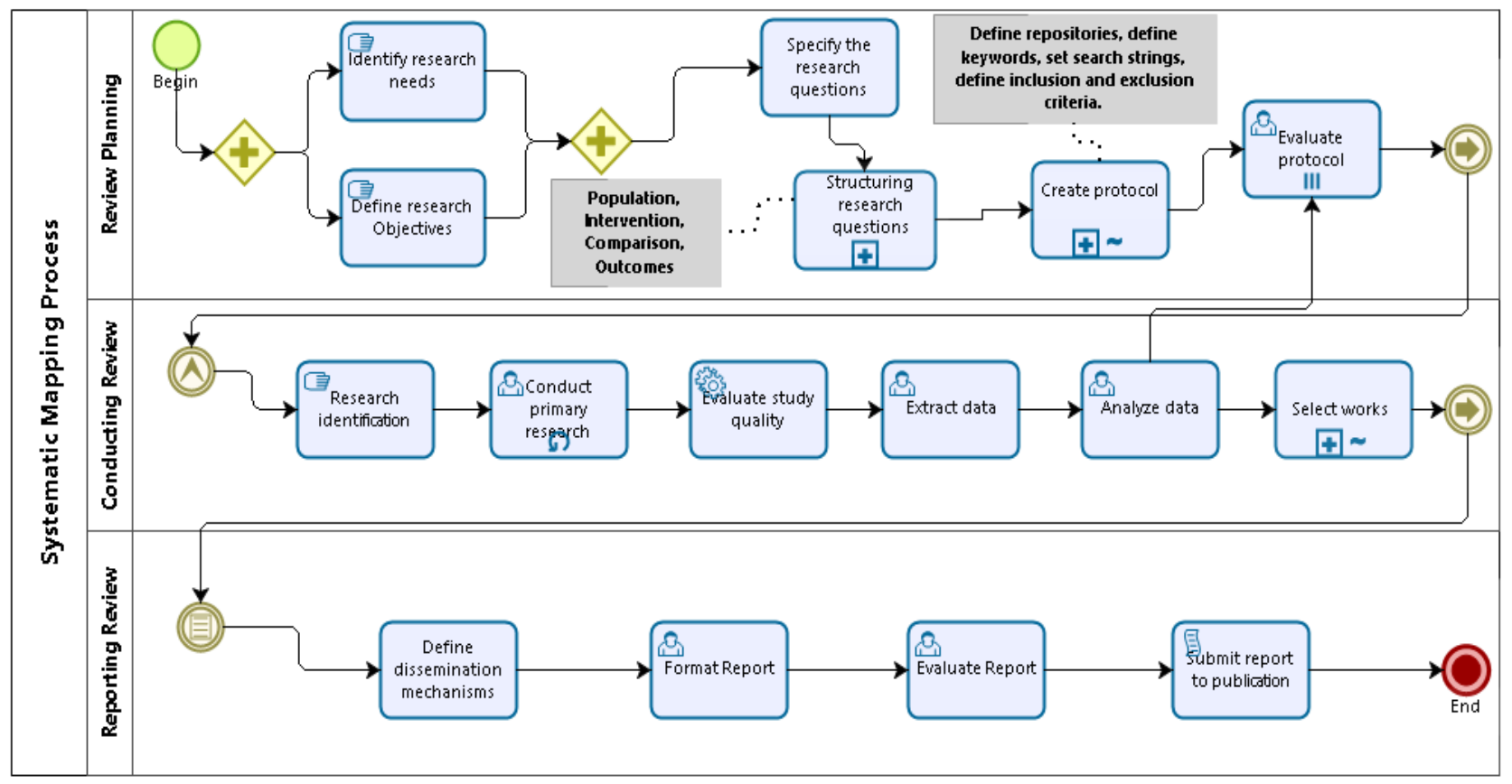

Fig. 1. Framework of systematic mapping process.

\subsection{Review Protocol}

Table 1 displays the protocol adopted in this research. It follows the guidelines of [7], [8] and [12] with some items suppressed or appearing in an order exclusively appropriate to this work.

Table 1. Protocol Adopted for Review

Id Protocol Topics $\quad$ Definition




\begin{tabular}{|c|c|c|}
\hline 1 & Context & Conduct a systematic mapping on the application of TOC to SPD. \\
\hline 2 & Objectives & $\begin{array}{l}\text { Evaluate primary studies available electronically on the chosen repositories to find } \\
\text { gaps and research opportunities on the application of TOC to SPD. }\end{array}$ \\
\hline 3 & Scope of research & Complete papers in digital libraries. \\
\hline 4 & Search methods & Search engines to perform automated search in the chosen \\
\hline 5 & Search questions & Definition of primary $(\mathrm{Pq})$ and secondary $(\mathrm{Sq})$ questions. \\
\hline 6 & Selection procedures & $\begin{array}{l}\text { The selection procedures will follow the following reading order: (1) title of the work; } \\
\text { (2) abstract; and (3) full text. }\end{array}$ \\
\hline 7 & Filters & The filters applied will establish the inclusion and exclusion criteria. \\
\hline 8 & $\begin{array}{l}\text { Data extraction } \\
\text { procedure }\end{array}$ & $\begin{array}{l}\text { The data extraction procedures were performed in three steps: (1) filling in a data } \\
\text { extraction report (in a table format) containing: title, authors, year of publication, } \\
\text { number of pages, keywords, repositories and a note for ranking; (2) application of } \\
\text { filters according to inclusion and exclusion criteria; and (3) ranking and discursive } \\
\text { analysis on the selected primary studies. }\end{array}$ \\
\hline 9 & Analysis Procedure & $\begin{array}{l}\text { Correlational analysis of the work with the thematic area of the research according to } \\
\text { the terms and search strings. }\end{array}$ \\
\hline 10 & Packing & $\begin{array}{l}\text { Finishing work stage that will result in a technical report containing the entire review } \\
\text { process to be inserted in a doctoral thesis session. }\end{array}$ \\
\hline
\end{tabular}

The following sessions will present the topics of the protocol from the Id 5. This is because the topics 1 Context, 2 - Objectives 3 - Scope of research and 4-Search methods are already defined in Table II.

\subsection{Search Targets}

Targets are the electronic repositories explored in this research. The targets were selected as sources of research of primary studies indexed and categorized by their electronic search engines and their digital libraries separated by research area (session and subsections), as shown in the Table 2.

Table 2. Target Repositories

\begin{tabular}{lll}
\hline \hline Target & Session & Subsections \\
\hline ACM Digital Library (ACM) & Computing Literature & $\begin{array}{l}\text { Science Computing and } \\
\text { Software Engineering }\end{array}$ \\
\hline Elsevier-Science Direct (ESD) & $\begin{array}{l}\text { Physical Sciences and } \\
\text { Engineering }\end{array}$ & \begin{tabular}{l} 
Computer Science \\
\hline Google Scholar ${ }^{1}(\mathrm{GS})$
\end{tabular} \\
\hline Computer Science & $\begin{array}{l}\text { Software Engineering and } \\
\text { Process Optimization }\end{array}$ \\
\hline IEEE Xplore (IX) & $\begin{array}{l}\text { IEEE Transaction } \\
\text { Computers }\end{array}$ & $\begin{array}{l}\text { IEEE Transaction on Software } \\
\text { Engineering }\end{array}$ \\
\hline Scopus (Scp) & Computer Science & Software Engineering \\
\hline Springer Link (SL) & Computer Science & $\begin{array}{l}\text { Information Systems and } \\
\text { Applications }\end{array}$ \\
\hline
\end{tabular}

\subsection{Search Criteria Adopted}

The most common search criterion is based on the adoption of keywords [6], [12] and [16]. Table III presents the terms used in this work.

Table 3. Terms used in Search Strings

\begin{tabular}{l|c|l}
\hline \hline \multicolumn{1}{c|}{ Keywords } & Acronyms & \multicolumn{1}{c}{ Expectancy } \\
\hline Theory Of Constraints & TOC & Main reference for the composition of search strings \\
\hline $\begin{array}{l}\text { Software Process } \\
\text { Imprtware Process }\end{array}$ & SP & Publications that link the use of TOC to SP \\
\hline $\begin{array}{l}\text { Software Process } \\
\text { Optimization }\end{array}$ & $S P O$ & Publications on improving SP focusing on the use of TOC \\
\hline Process Optimization & $P O$ & Publications that involve process optimization in general with \\
\hline \hline & & the use of TOC \\
\hline
\end{tabular}

\footnotetext{
${ }^{1}$ The target Google Scholar does not have specific sessions and subsections. To solve the problem, three keywords were searched for refinement and to define search area (Session: Computer Science) and subarea (Sub session: Software Engineering and Process Optimization)
} 
The search strings constructed from the terms added to the operators, AND $(\wedge)$ and OR $(v)$. In order to restrict the number of undesired results found during the search, two closures, $\{", "\}$ and parentheses $\{()$,$\} ,$ were included, as shown in Table 4.

Table 4. Search Strings

\begin{tabular}{l}
\hline \hline Search strings with the operator $\wedge$ (AND) and the parentheses and quotes closings. \\
\hline ("Theory of Constraints $\wedge$ Software Process $\wedge$ Software Process Optimization $\wedge$ Software Process \\
Improvement $\wedge$ Process Optimization") \\
\hline Search strings with the operator $\vee(\mathbf{O R})$ and the parentheses and quotes closings. \\
\hline ("Theory of Constraints $\wedge$ Software Process $\vee$ Software Process Optimization $\vee$ Software Process \\
Improvement $\vee$ Process Optimization")
\end{tabular}

The purpose of the first string is to perform concatenated searches by associating the term Theory of Constraints with all other terms adopted and in this way attempt to direct the search and find papers directly correlated with TOC in SPD. The second string enables searches to perform by associating Theory of Constraints with one of the keywords. The intention is to display works that may have been suppressed by the first string.

\subsection{Research Questions}

The research questions establish the direction and the identification of the searches in the repositories from the objectives of the research. The objectives are translated through the search questions, which are defined to align the searches to the proposed theme. We define two types of questions: (1) question (Pq); And (2) Secondary question $(S q)$. The following topics present the issues that have been elaborated and used to delineate this secondary study.

- $P q$ - Is it possible to apply TOC in the software development process?

$P q$ defines and directs the research objective, supported by questions $S q 1, S q 2, S q 3, S q 4$ and $S q 5$.

- Sq1 - What kind of application can we have of TOC with the software development process?

- Sq2 - Can TOC be applied to identify bottlenecks in the SPD?

- Sq3 - How can the use of TOC help in the optimization of software processes?

- Sq4 - Can the use of TOC associated with optimization techniques in other areas with proven efficacy be associated with the software process?

- Sq5 - With which tools, techniques, skills, processes and methodologies, with a focus on optimization and improvement of the software process, can the TOC be applied?

Sq4 looks for a direct relation of the use of TOC in other areas of knowledge that can be associated or applied in software process optimization. $S q 5$ seeks to identify tools, techniques, and optimization methods that can be used with TOC

\section{Work Selection Method}

The analysis and selection of the works is started after the search in each target repository. All papers were analyzed according to the central theme, their relevance and depth. For this, some criteria were determined to consider the relevant documents for this secondary study, such as: (1) inclusion criteria; (2) exclusion criteria; (3) evaluation criteria; and (4) selection criteria.

The inclusion and exclusion criteria were based on the search queries created in session 2.5. The evaluation and selection criteria were based on a ranking system, specifically developed to meet the needs of this work. 


\subsection{Inclusion Criteria}

The following topics present the inclusion criteria adopted in this research. The work must:

- 1 - be related to the TOC;

- 2 - be related to SPD or optimization of software processes;

- 3 - The work must be complete (available in full) and published in one of the target repositories.

- 4 - be written in English;

- 5 - contain in the title and in the abstract some relation with the central theme of this research.

\subsection{Exclusion Criteria}

The works can be excluded in three stages:

- Sudden exclusion: either work is outside the adopted period (2006 - 2016) or is repeated;

- Exclusion after initial analysis: work has no relation to the central theme of this research or is not aligned with the context of this research;

- Exclusion after detailed analysis: the work does not have sufficient depth in relation to the proposed theme, or does not meet any of the research questions.

\subsection{Evaluation Criteria}

The results were analyzed in two phases. The first phase consists of:

- observing and interpreting the title of the works;

- analyzing the key words used in the work;

- reading the abstract and conclusion of the work.

The primary studies selected after the first phase are stored in bibliographic reference management software for detailed analysis.

The detailed analysis is the second phase of the selection process and consists of an in-depth analysis of the content, mainly focusing on the methods, models, techniques and tools used in the primary study.

\subsection{Selection Criteria}

During the evaluation phase, the pre-selected works are "ranked" with a score (A, B or C), being (A>80\%) $(B>65 \%<A)$ and $(C>50 \%<B)$. The evaluation should be carried out based on the inclusion and exclusion criteria, and with the attribution of weights applied as follows:

- Score A: weight 3, for works with strong correlation with (Pq) and at least one secondary question;

- Score B: weight 2, for works that partially meet $(\mathrm{Pq})$ and at least one secondary issue;

- Score C: weight 1, for works that are related to at least one of the secondary issues (Sq) and low correlation with the primary question.

In order to be selected, all results must pass the inclusion criteria and be properly ranked.

\section{Analysis and Results}

The results of a literature review can be presented using tables, numerical results, graphs and statistical analyzes [5]. In this study, the results will be presented as a data table, since this type of representation is easy to visualize and understand, and also because it serves the purpose of the study.

The analysis performed and their respective results, as presented in sections 4.1, 4.2 and 4.3, through Tables 3, 4, 5, 6 and 7, was done according to the selection method described in section 3, using the inclusion criteria (section 3.1), exclusion criteria (section 3.2), evaluation criteria (section 3.3) and selection criteria (section 3.4). 


\subsection{Search Results}

Table $\mathrm{V}$ presents the overall results of the search, having already applied the initial criteria of analyzes.

Table 4. Initial Results Obtained (1st Phase of the Analysis)

\begin{tabular}{|c|c|c|c|c|c|c|c|c|c|c|c|c|}
\hline \multicolumn{13}{|c|}{ Overall Search Results } \\
\hline \multirow{2}{*}{ Search Strings } & \multicolumn{6}{|c|}{ Initial Results of Search } & \multicolumn{6}{|c|}{ Excluded by Filtering } \\
\hline & $G S$ & $I X$ & $S L$ & ACM & ESD & Scp & $G S$ & $I X$ & $S L$ & ACM & ESD & Scp \\
\hline $\mathrm{TOC} \wedge \mathrm{SP} \wedge \mathrm{SPI} \wedge \mathrm{SPO} \wedge \mathrm{PO}$ & 58 & 13 & 26 & 33 & 27 & 16 & 31 & 7 & 16 & 21 & 17 & 12 \\
\hline $\mathrm{TOC} \wedge \mathrm{SP} \vee \mathrm{SPI} \vee \mathrm{SPO} \vee \mathrm{PO}$ & 27 & 24 & 15 & 32 & 15 & 11 & 9 & 13 & 12 & 11 & 13 & 9 \\
\hline Total & 75 & 37 & 41 & 65 & 42 & 9 & 35 & 20 & 28 & 34 & 31 & 21 \\
\hline
\end{tabular}

The numerical difference between the fields "Initial Results of Search" and "Excluded by Filtering" from Table 5, represents the data of the field "Pre-selected" of the Table 6, included by initial analysis. Table 6 also shows the number of works excluded after the initial analysis.

Table 5. Initial Analysis (2nd Phase of the Analysis)

\begin{tabular}{|c|c|c|c|c|c|c|c|c|c|c|c|c|}
\hline \multicolumn{13}{|c|}{ Initial Analysis } \\
\hline \multirow{2}{*}{ Search Strings } & \multicolumn{6}{|c|}{ Pre-Selected } & \multicolumn{6}{|c|}{ Excluded by Initial Analysis } \\
\hline & GS & $I X$ & $S L$ & ACM & $E S D$ & Scp & $G S$ & $I X$ & $S L$ & ACM & $E S D$ & Scp \\
\hline$T O C \wedge S P \wedge S P I \wedge S P O \wedge P O$ & 27 & 6 & 10 & 12 & 10 & 4 & 14 & 4 & 7 & 7 & 6 & 2 \\
\hline$T O C \wedge S P \vee S P I \vee S P O \vee P O$ & 18 & 11 & 3 & 21 & 2 & 3 & 6 & 2 & 1 & 13 & 2 & 1 \\
\hline Total & 45 & 17 & 13 & 33 & 12 & 7 & 20 & 6 & 8 & 20 & 8 & 3 \\
\hline
\end{tabular}

Following the same criterion for data visualization, the values presented in the field "Analyzed" of table VII, translate the numerical difference between the fields "Pre-selected" and "Excluded by Initial Analysis" from Table VI. Table VII also shows the field "Included", which is the selected works after the final analysis.

Table 6. Final Analysis (3rd Phase of the Analysis)

\begin{tabular}{c|c|c|c|c|c|c|c|c|c|c|c|c}
\hline \hline \multicolumn{10}{c}{ Final Analysis } \\
\hline \multirow{2}{*}{ Search Strings } & $\boldsymbol{G S}$ & $\boldsymbol{I} \boldsymbol{X}$ & $\boldsymbol{S L}$ & $\boldsymbol{A C M}$ & $\boldsymbol{E S D}$ & $\boldsymbol{S c p}$ & $\boldsymbol{G S}$ & $\boldsymbol{I X}$ & $\boldsymbol{S L}$ & $\boldsymbol{A C M}$ & $\boldsymbol{E S D}$ & $\boldsymbol{S} \boldsymbol{S p}$ \\
\hline $\mathrm{TOC} \wedge \mathrm{SP} \wedge \mathrm{SPI} \wedge \mathrm{SPO} \wedge \mathrm{PO}$ & 13 & 2 & 3 & 5 & 4 & 2 & 8 & 1 & 1 & 4 & 2 & 2 \\
\hline $\mathrm{TOC} \wedge \mathrm{SP} \vee \mathrm{SPI} \vee \mathrm{SPO} \vee \mathrm{PO}$ & 12 & 9 & 2 & 8 & 0 & 1 & 6 & 8 & 3 & 5 & 0 & 0 \\
\hline Total & $\mathbf{2 5}$ & $\mathbf{1 1}$ & $\mathbf{4}$ & $\mathbf{1 3}$ & $\mathbf{4}$ & $\mathbf{3}$ & $\mathbf{1 4}$ & $\mathbf{2}$ & $\mathbf{4}$ & $\mathbf{4}$ & $\mathbf{2}$ & $\mathbf{1}$ \\
\hline
\end{tabular}

\subsection{Final Results}

Table VIII presents the final results of the literature review, with 24 papers selected in accordance with the search queries and the inclusion and exclusion criteria adopted in this study.

Table 7. Final Results

\begin{tabular}{|c|c|c|c|c|c|c|c|c|}
\hline \multicolumn{9}{|c|}{ Final Results: Selected / Included Works } \\
\hline Search Strings & $\begin{array}{l}\text { Google } \\
\text { Scholar }\end{array}$ & $\begin{array}{c}\text { IEEE } \\
\text { Xplorer }\end{array}$ & $\begin{array}{c}\text { Springe } \\
\text { r Link }\end{array}$ & $A C M D L$ & $\begin{array}{c}\text { Elsevie } \\
r \\
\text { Science } \\
\text { Direct }\end{array}$ & Scopus & $\begin{array}{c}\text { Total } \\
\text { per } \\
\text { String }\end{array}$ & $\begin{array}{l}\text { \% per } \\
\text { String }\end{array}$ \\
\hline $\mathrm{TOC} \wedge \mathrm{SP} \wedge \mathrm{SPI} \wedge \mathrm{SPO} \wedge \mathrm{PO}$ & 5 & 1 & 2 & 1 & 2 & 0 & 11 & $45,83 \%$ \\
\hline $\mathrm{TOC} \wedge \mathrm{SP} \vee \mathrm{SPI} \vee \mathrm{SPO} \vee \mathrm{PO}$ & 6 & 1 & 2 & 3 & 0 & 1 & 13 & $54,17 \%$ \\
\hline Total per Target & 11 & 2 & 4 & 4 & 2 & 1 & 24 & $100 \%$ \\
\hline$\%$ Selected by Target & $45,83 \%$ & $8,33 \%$ & $16,67 \%$ & $16,67 \%$ & $8,33 \%$ & $4,17 \%$ & $100 \%$ & \\
\hline
\end{tabular}




\subsection{Selected Works}

Table 8 presents the list of selected papers, organized by score and search targets. In addition, the table also presents a correlation of selected works with the terms used in the construction of the search strings and related search issues.

Table 8. Selected Works

\begin{tabular}{|c|c|c|c|c|c|}
\hline \multicolumn{6}{|c|}{ Selected Works } \\
\hline Target & Authors & Title & $\begin{array}{l}\text { Associated } \\
\text { Terms }\end{array}$ & $\begin{array}{c}\text { Related } \\
\text { Questions }\end{array}$ & Score \\
\hline \multirow{11}{*}{$\begin{array}{l}\bar{\pi} \\
\frac{\pi}{0} \\
\frac{\Xi}{0} \\
\omega \\
0 \\
0 \\
0 \\
0 \\
0\end{array}$} & $\begin{array}{l}\text { Condori-Fernandez, } \\
\text { et.al (2009) }\end{array}$ & $\begin{array}{l}\text { A Roadmap Approach For Implementing } \\
\text { Theory of Constraints In Manufacturing } \\
\text { Organizations. }\end{array}$ & TOC, PO & $\mathrm{Sq} 4, \mathrm{Sq} 5$ & $\mathrm{C}$ \\
\hline & Ellis (2011) & $\begin{array}{l}\text { A Theory of Constraints Service Systems } \\
\text { Improvement Method: Case of the Airline } \\
\text { Turnaround Problem. }\end{array}$ & TOC, SPI & $\mathrm{Sq} 4, \mathrm{Sq} 5$ & $\mathrm{C}$ \\
\hline & $\begin{array}{l}\text { Murauskaite, } \\
\text { Adomauskas, } \\
(2008) \\
\end{array}$ & $\begin{array}{l}\text { Bottlenecks in Agile Software } \\
\text { Development Identified Using Theory of } \\
\text { Constraints (TOC) Principles. }\end{array}$ & TOC, SP, SPI & $\begin{array}{l}\mathrm{Pq}, \mathrm{Sq} 1 \\
\mathrm{Sq} 2\end{array}$ & B \\
\hline & $\begin{array}{l}\text { Feng, Gui, Ling, } \\
\text { (2007) }\end{array}$ & $\begin{array}{l}\text { Explorations of Thinking Process based } \\
\text { on TOC. }\end{array}$ & TOC & $\mathrm{Sq} 4, \mathrm{Sq} 5$ & $\mathrm{C}$ \\
\hline & Gülsün, et al (2012) & $\begin{array}{l}\text { Improving System Performance: The } \\
\text { Theory of Constraints and an Application } \\
\text { in a Production Firm. }\end{array}$ & TOC, PO & $\mathrm{Sq} 4, \mathrm{Sq} 5$ & $\mathrm{C}$ \\
\hline & $\begin{array}{l}\text { Staron, Meding } \\
\quad(2011)\end{array}$ & $\begin{array}{l}\text { Monitoring Bottlenecks in Agile and Lean } \\
\text { Software Development Projects - A } \\
\text { Method and Its Industrial Use. }\end{array}$ & TOC, SP & $\begin{array}{l}\mathrm{Pq}, \mathrm{Sq} 1 \\
\mathrm{Sq} 2\end{array}$ & $\mathrm{C}$ \\
\hline & Rezaie, et al (2010) & $\begin{array}{l}\text { Theory of Constraints and Particle } \\
\text { Swarm Optimization Approaches for } \\
\text { Product Mix Problem Decision. }\end{array}$ & TOC, PO & $\mathrm{Sq} 4, \mathrm{Sq} 5$ & $\mathrm{C}$ \\
\hline & Bailey (2009) & $\begin{array}{l}\text { The Theory of Constraints: Productivity } \\
\text { Metrics in Software Development }\end{array}$ & TOC, SP, SPI & $\begin{array}{l}\text { Pq, Sq1, } \\
\text { Sq2 }\end{array}$ & A \\
\hline & Almeida (2013) & $\begin{array}{l}\text { Using the Theory of Constraints to } \\
\text { Analyze Bottlenecks in the Freight } \\
\text { Transportation System: the Case of the } \\
\text { Center-north Corridor in Brazil. }\end{array}$ & TOC, PO & $\mathrm{Sq} 4, \mathrm{Sq} 5$ & $\mathrm{C}$ \\
\hline & $\begin{array}{c}\text { Trojanowsk, Pająk } \\
\text { (2010) }\end{array}$ & $\begin{array}{l}\text { Using The Theory Of Constraints To } \\
\text { Production Processes Improvement. }\end{array}$ & TOC, PO & $\begin{array}{l}\mathrm{Pq}, \mathrm{Sq} 4 \\
\mathrm{Sq} 5\end{array}$ & B \\
\hline & $\begin{array}{l}\text { Bakhtiyari, et al. } \\
\text { (2013) }\end{array}$ & $\begin{array}{l}\text { Using Theory of Constraints in selecting } \\
\text { product mix. }\end{array}$ & TOC, PO & $\mathrm{Sq} 4, \mathrm{Sq} 5$ & $\mathrm{C}$ \\
\hline 气̊̀̆ & $\begin{array}{l}\text { Kasemset, } \\
\text { Kachitvichyanukul } \\
\text { (2012) }\end{array}$ & $\begin{array}{l}\text { A PSO-based procedure for a bi-level } \\
\text { multi-objective TOC-based job-shop } \\
\text { scheduling problem }\end{array}$ & TOC, PO & $\mathrm{Sq} 4, \mathrm{Sq} 5$ & $\mathrm{C}$ \\
\hline \multirow{2}{*}{ 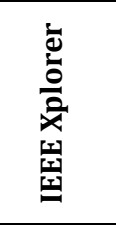 } & Lin (2009) & $\begin{array}{l}\text { Using TOC Thinking Process Tools to } \\
\text { Improve Safety Performance. }\end{array}$ & TOC, PO & $\begin{array}{l}\mathrm{Pq}, \mathrm{Sq} 4 \\
\mathrm{Sq} 5\end{array}$ & $\mathrm{C}$ \\
\hline & $\begin{array}{l}\text { Ribeiro et al. } \\
\quad(2015)\end{array}$ & $\begin{array}{l}\text { Bottleneck Identification in Software } \\
\text { Development Processes: A Proposal } \\
\text { Based on the Principles of the Theory of } \\
\text { Constraints - Experimentation Report }\end{array}$ & $\begin{array}{l}\text { TOC, SP, } \\
\text { SPI, SPO }\end{array}$ & $\begin{array}{l}\text { Pq, Sq1, } \\
\text { Sq2, Sq3, }\end{array}$ & A \\
\hline \multirow{4}{*}{ 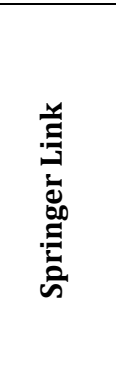 } & Geri, Ahituv (2008) & $\begin{array}{l}\text { A Theory of Constraints approach to } \\
\text { interorganizational systems } \\
\text { implementation. }\end{array}$ & TOC, PO & $\mathrm{Sq} 4, \mathrm{Sq} 5$ & $\mathrm{C}$ \\
\hline & $\begin{array}{l}\text { Rhee, Cho, Bae } \\
\quad(2010)\end{array}$ & $\begin{array}{l}\text { Increasing the efficiency of business } \\
\text { processes using a theory of constraints. }\end{array}$ & TOC, PO & $\begin{array}{l}\mathrm{Pq}, \mathrm{Sq} 4 \\
\mathrm{Sq} 5\end{array}$ & B \\
\hline & $\begin{array}{l}\text { Baptista, et.al } \\
\quad(2013)\end{array}$ & $\begin{array}{l}\text { Profit optimization in machining service } \\
\text { providers using principles of the Theory } \\
\text { of Constraints. }\end{array}$ & TOC, PO & $\mathrm{Sq} 4, \mathrm{Sq} 5$ & $\mathrm{C}$ \\
\hline & $\begin{array}{l}\text { Kilger, Wetterauer } \\
\text { (2007) }\end{array}$ & The Selection Process. & TOC, PO & $\mathrm{Sq} 4, \mathrm{Sq} 5$ & $\mathrm{C}$ \\
\hline$\Xi-$ & Zhou, Rose (2009) & $\begin{array}{l}\text { A Bottleneck Detection and Dynamic } \\
\text { Dispatching Strategy for Semiconductor }\end{array}$ & TOC, PO & $\mathrm{Sq} 4, \mathrm{Sq} 5$ & $\mathrm{C}$ \\
\hline
\end{tabular}




\begin{tabular}{|c|c|c|c|c|c|}
\hline & & Wafer Fabrication Facilities. & & & \\
\hline & $\begin{array}{l}\text { Sengupta, et al } \\
\text { (2008) }\end{array}$ & A New Method for Bottleneck Detection. & TOC, PO & $\begin{array}{l}\text { Pq, Sq4 } \\
\text { Sq5 }\end{array}$ & B \\
\hline & $\begin{array}{l}\text { Hasgul, Kartal } \\
\text { (2007) }\end{array}$ & $\begin{array}{l}\text { Analyzing A Drum-Buffer-Rope } \\
\text { Scheduling System Executability Through } \\
\text { Simulation. }\end{array}$ & TOC, $\mathrm{PO}$ & $\begin{array}{l}\text { Pq, Sq4 } \\
\text { Sq5 }\end{array}$ & $\mathrm{C}$ \\
\hline & $\begin{array}{l}\text { Lemessi, et.al } \\
\quad(2012)\end{array}$ & $\begin{array}{l}\text { Semi-Automatic Simulation-Based } \\
\text { Bottleneck Detection Approach }\end{array}$ & TOC, PO & $\mathrm{Sq} 4, \mathrm{Sq} 5$ & $\mathrm{C}$ \\
\hline \multirow{2}{*}{ 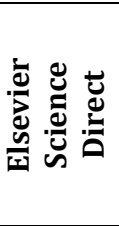 } & Xiao, et al. (2011) & $\begin{array}{l}\text { Modified Active Set Projected Spectral } \\
\text { Gradient Method for Bound Constrained } \\
\text { Optimization. }\end{array}$ & TOC, PO & $\mathrm{Sq} 4, \mathrm{Sq} 5$ & $\mathrm{C}$ \\
\hline & $\begin{array}{l}\text { Barreto, et al } \\
\quad(2008)\end{array}$ & $\begin{array}{l}\text { Staffing a Software Project: A Constraint } \\
\text { Satisfaction and Optimization-Based } \\
\text { Approach. }\end{array}$ & PO & $\mathrm{Sq} 4, \mathrm{Sq} 5$ & $\mathrm{C}$ \\
\hline
\end{tabular}

\subsection{Considerations About Selected Works}

The works were ranked according to the score explained in section 3.4. When we observe the relationship between search terms and search questions, some considerations could be made.

- Work with Score C: in general the work does not have a direct relationship with the primary question (Pq). But, we think that the used methods can be applied in software development process. These works are directly related to the questions (Sq4) and (Sq5) and with the term TOC and PO.

- Work with Score B: have a low correlation with (Pq), but we believe that the methods used in the primary study can be used or applied in the software process. The work of Murauskaite, Adomauskas, (2008), has a strong connection with the use of TOC in software processes and the terms (SP) and (SPI), but does not present a method or any efficient measurement for the identification of bottlenecks in Software Process or a metric to Software Process Improvement. This study also does not mention how the work was conducted, reason for which it was assigned weight 2 and Score B.

- Work with Score A: For these works the score A was assigned because they had some relation with the (Pq) and the questions (Sq1) and (Sq2). Furthermore, the papers are also related to the terms (SP) and (SPI). However, they do not exploit the effective application of TOC in the software development process. The work of Ribeiro et al. (2015), is an initial study and reports only the conduct of an experiment to identify bottlenecks in the Software Development Process (SDP). The work of Bailey et al. (2009), basically shows in which areas the TOC can be applied in software development, but does not show how to use TOC for this purpose. The work also suggests that TOC can be used in measurements aimed at agile development, mainly with Extreme Programming (XP), Software Development Lifecycle (SDLC), Feature Driven Development (FDD), Scrum and Rapid Application Development (RAD).

\section{Research Opportunities}

This study demonstrated that, although widely exploited in manufacturing processes, there is a large research front involving the application of TOC to software processes. Practically, there is no existent work related to the process of software development.

The following sections will present the research gaps, identified in this study, relating the application of TOC to Software Process Development.

\subsection{Gaps Found}

During the analysis of the results, some gaps involving the central theme of this research were identified and recorded in the log book, even in the papers with highest scores. The main gaps identified as well as some observations are presented in the topics below. 
- Use of the TOC in Software Process Development: it is rarely addressed or discussed. Papers present very shallow conceptualizations and contextualization about applying the TOC to SPD.

- Bottlenecks Identification in SPD: All the analyzed papers that use TOC in the identification of bottlenecks are related to the productive environment of the manufacturing industry or logistics systems. The gap detected is in applying bottleneck identification using the TOC in software development processes. This may involve using, as a basis, the methods and techniques applied in industrial production processes.

- Use of the TOC in Software Process Improvement: The TOC is known as a philosophy of continuous improvement. As not a single work has been identified that relates the TOC to SPD, it was not possible to identify any work that applied to TOC in software process improvement. This may be a good research front.

- Use of the TOC in Software Process Optimization: The use of optimization techniques in manufacturing processes is largely explored, but neither work has any relation to the software development process. The search did not return any related results, thus presenting a large gap, with ample research opportunity, mainly with the use of optimization techniques such as heuristics and meta heuristics to adjust and improve the software process.

- The TOC principles: The 5 steps of TOC, the Drum, Buffer and Rope method, Think Process and the Concepts of continuous improvement are not explored in most of the works analyzed, especially in the works involving the software process. Applying these concepts to SPD is a broad and challenging front.

\subsection{Research Opportunities Identified}

This study evidenced a lack of research that effectively addresses the use of TOC in SPD, indicating the existence of a large gap, with significant research opportunities both in the theoretical field, as in the practical field.

However, in order to help the researchers interested in this theme, a set of sub-areas that can be transformed in research opportunities is presented in Table X.

Table 9. Research Opportunities Per Area

\begin{tabular}{l|c|c|c}
\hline \multirow{2}{*}{\multicolumn{1}{c}{ Themes / Sub-Areas }} & \multicolumn{2}{c}{ Type of Studies } & \multirow{2}{*}{ Status: Identified Situation } \\
\cline { 2 - 4 } & Theoretical & Practical & \\
\hline Software Development & Yes & Yes & Open area \\
\hline Software Process & Yes & Yes & Open area \\
\hline Software Process Improvement & Yes & Yes & Open area \\
\hline Software Process Optimization & Yes & Yes & Open area \\
\hline Software Project Management & Yes & Yes & Open area \\
\hline Agile Software Development & Yes & Yes & Partially open area \\
\hline Software Quality & Yes & Yes & Open area \\
\hline Application in Software Test Process & Yes & Yes & Open area \\
\hline Application in the Software Industry & Yes & Yes & Open area \\
\hline Experimental Software Engineering & Yes & Yes & Partially open area \\
\hline
\end{tabular}

The areas identified as partially open indicate that there is some work done that employs the TOC in the SPD, however these works do not present solidity in terms of either methodology or application.

\section{Conclusion}


A literature review is a difficult and costly process that requires time, discipline and care in the elaboration of criteria for a good analysis and classification of the works.

During the period in which this research was carried out, many discoveries were made, among them the importance of conducting a good secondary study before beginning any research, regardless of the area. However, the most important discovery was evidence that TOC has a broad application front in the software development process, according to the gaps identified.

Exploring and applying optimization techniques, heuristics and metaheuristics in software development process is also a great possibility for research. Aligning these two fronts is a challenge. Despite this challenge it could promote considerable improvements in the software process, be it in minimizing costs, reducing production time and delivery (lead times) or in maximizing productive results.

In future moments, we intend to explore the research opportunities identified in this study. The first front to be explored is the possibility of developing a method to identify bottlenecks in the software process, using the principles of Theory of Constraints and to model and adjust the software development process.

\section{References}

[1] Goldratt, E. M., \& Cox, J. (2006). The goal: A process of ongoing improvement. São Paulo - SP; Brazil.

[2] Goldratt, E. M. (2002). The Critical Chain; Reprint and Translated, Nobel Press, São Paulo - SP; Brazil.

[3] Easterbrook, S., \& Singer, J., Storey, M., \& Damian, D. (2008). Selecting empirical methods for software engineering research. Guide to Advanced Empirical Software Engineering.

[4] Biolchini, J., Mian, P., Natali, A., \& Travassos, G. (2005). Systematic review in software engineering. Technical Report.

[5] Brereton, P., Kitchenham, B. A., Budgen, D., Turner, M., \& Khalil, M. (2007). Lessons from applying the systematic literature review process within the software engineering domain. Technical report.

[6] Kitchenham, B. (2004). Procedures for performing systematic reviews. Software Engineering Group, Department of Computer Science, Keele University Keele - UK.

[7] Kitchenham, B., \& Charters, S. (2007). Guidelines for performing systematic literature reviews in software engineering; EBSE Technical Report, Keele University and Durham University; Keele and Durhan - UK.

[8] Kalus, G., \& Kuhrmann, M. (2013). Criteria for software process tailoring: A systematic review. Proceedings of the ICSSP 2013 International Conference on Software and System Process (pp. 171-180).

[9] Pedreira, O., Piattini, M., Luaces, M. R., \& Brisaboa, N. R. (2007). A systematic review of software process tailoring; ACM sigsoft software engineering notes.

[10] Babar, M. A., \& Gorton, I. (2009). Software architecture review: The state of practice. Computer, 42(7), 26-32.

[11] Biolchini, J. C. A., Mian , P. G., Natali, A. C. C., Conte, T. U., \& Travassos, G. H. (2007). Scientific research ontology to support systematic review in software engineering. Advanced Eng. Informatics Journal, 21(2), 133-151.

[12] Gupta, A., Bhardwaj, A., \& Kanda, A. (2010). Fundamental concepts of theory of constraints: An emerging philosophy, world academy of science, engineering and technology. International Journal of Social, Behavioral, Educational, Economic, Business and Industrial Engineering, 4(10).

[13] Islam, A. M. M., Gorschek, T., Unterkalmsteiner, M., Feldt, R., Permadi, R. B., \& Cheng, C. K. (2012). Evaluation and measurement of software process improvement: A systematic literature review. IEEE Transactions on Software Engineering, 38(2), 398-424.

[14] Kim, S., Mabin, V. J., \& Davies, J. (2008). The theory of constraints thinking processes: Retrospect and prospect. International Journal of Operations \& Production Management, 28(2), 155-184. 
[15] Kitchenham, B., Brereton, O. P., Budgen, D., Turner, M., Bailey, J., \& Linkman, S. (2009). Systematic literature reviews in software engineering, Journal of Information and Software Technology.

[16] Rahman, S. (1998). Theory of constraints: A review of the philosophy and its applications, Perth. Australia International Journal of Operations e Production Management.

[17] Sulayamam, M. \& Mendes, E. (2009). A systematic literature review of software process improvement in small and medium web companies; Advances in software engineering communications in computer and information science.

[18] Goldratt, E. M., \& Kishira, Y. (2009). CCPM and TOC — A Revolution in Japan. Revista Mundo PM, Ed. 28, Brazil; 2009.

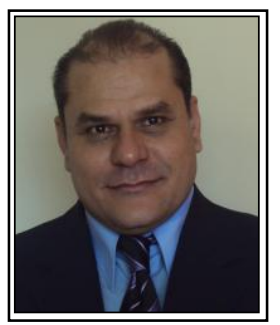

Sildenir Alves Ribeiro holds a bachelor's degree in computer science from the University of Cuiabá (UNIC), is specialist in systems administration from the Federal University of Lavras (UFLA), holds a master's degree in informatics from the Federal University of Espírito Santo (UFES) and a doctoral student in informatics from Tércio Pacitti Institute of Research and Computational Applications of the Federal University of Rio de Janeiro (UFRJ). He is currently a professor at the Federal Center for Technological Education of Rio de Janeiro (CEFEFT/RJ), at Industrial Automation Coordination. Has experience in Computer Science, with emphasis on Software Engineering and Information Systems. He is active mainly in the following topics: strategic management of IT, project management, software processes, analysis and development of systems.

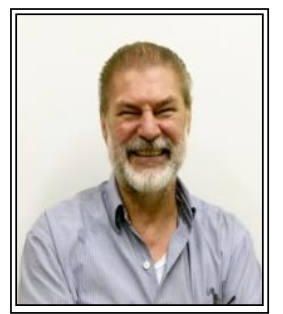

Eber Assis Schmitz holds a degree in electronic engineering from the Federal University of Rio Grande do Sul (UFRGS), has a master's degree in electrical engineering from the Federal University of Rio de Janeiro (UFRJ) and a PhD in computing and control from Imperial College. He is currently an associate professor at the Federal University of Rio de Janeiro, in the Computer Science Department and the Postgraduate Program in Informatics (PPGI), at the Tércio Pacitti Institute of Research and Computer Applications at the Federal University of Rio de Janeiro (UFRJ). He has experience in the area of computer science, with emphasis on software engineering and information systems, acting mainly on the following topics: software modeling and specification, risk analysis in IT projects, software engineering economics, modeling and simulation of Software processes and business rules.

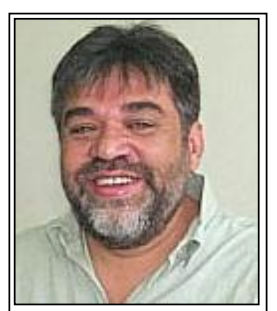

Antonio Juarez S. M. de Alencar holds a bachelor's degree in mathematics from the Federal University of Rio de Janeiro (UFRJ), has a master's degree in systems and computer engineering from the Federal University of Rio de Janeiro (UFRJ) and a DPhil. in Computer Science from the University of Oxford. He is currently professor of the Postgraduate Program in Informatics (PPGI) at the Federal University of Rio de Janeiro, from Tércio Pacitti Institute of Research and Computer Applications. He is an Information Technology Analyst at the Federal University of Rio de Janeiro (UFRJ). He has experience in the area of computer science, with emphasis on Analysis of IT Investments. He is active mainly in the following topics: risk analysis in software projects and economics software engineering. 


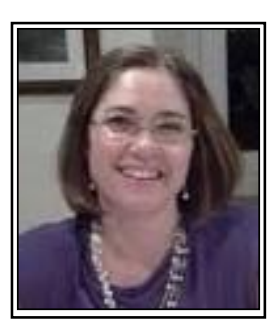

Mônica Ferreira da Silva holds a degree in informatics from the Federal University of Rio de Janeiro (UFRJ), is a specialist in project management from NCE / UFRJ, has a Master's degree in systems and computation engineering from COPPE / UFRJ and a doctor of science degree in administration from COPPEAD / UFRJ. She is currently a guest lecturer at the Federal University of Rio de Janeiro and coordinator of postgraduate courses at the Tércio Pacitti Institute of Research and Computer Applications. She has experience in the area of Administration, with emphasis on Information Technology Management. She is active mainly in the following topics: strategy and information systems, methodology of scientific research and adoption of technology. 